\title{
Peak periods and peak water demand: is there a need to review and revise?
}

\section{Introduction}

Water is critical to the economy, environment and communities. A healthy environment and safe, affordable and reliable water services are a must for people, jobs and a thriving community. ${ }^{1}$ For this to be achieved, water authorities must have a detailed understanding of the water use behaviour and requirements of their service region, especially for periods of high demand. With rapid population growth, especially in urban areas, and the impacts of climate change, there are a number of challenges that water management is currently facing. Global temperatures continue to rise with sixteen of the seventeen hottest years on record occurring this century.,3 The Bureau of Meteorology, Australia (BoM) and the Commonwealth Scientific and Industrial Research Organisation (CSIRO, Australia) in their recent publication on the state of the Australian climate state that the duration, frequency and intensity of extreme heat events have increased across large parts of Australia. ${ }^{4}$ These periods of extreme heat necessitate additional demand on basic services, including water.

\section{Peak periods - is there a definition?}

As the temperature and rainfall patterns change, a number of organisations with a diverse set of roles and responsibilities will be affected in different ways, such as:

a. Water authorities
i. Water supply
ii. Catchment Management Authorities

b. Emergency management authorities
i. Country Fire Authority (CFA)
ii. Police and ambulance services
iii. Hospitals and related medical services

c. Flood management
i. Catchment Management Authorities
ii. Local councils
iii. Transport services
iv. Road services

d. Basic services (Electricity, Gas)

e. State Emergency services

f. Department of Human Services (DHS)

\section{g. Soil and agricultural industries}

One of the common parameters of interest to these diverse organisations is 'peak period' when the demand on services is likely to be very high. As part of an investigation to re-define peak demands for planning dual water supply systems, a literature review was undertaken to determine the meaning of the term 'peak period' to different organisations. The major bodies investigated included

\author{
Volume 2 Issue I - 2018 \\ Ryan Davis,' Paul Young, ${ }^{3}$ Harpreet Kandra ${ }^{2}$ \\ 'Monash University Australia and Engineer, Infrastructure \\ Planning, Gippsland Water, Australia \\ ${ }^{2}$ Faculty of Science and Technology, Federation University, \\ Australia \\ ${ }^{3}$ Infrastructure Planning, Gippsland Water, Australia
}

Correspondence: Harpreet Kandra, Faculty of Science and Technology, Department of Water Engineering, Federation University,Australia, Email h.kandra@federation.edu.au

Received: November 07, 2017 | Published: January 30, 2018

the BoM; the Water Services Association of Australia (WSAA); the Intergovernmental Panel on Climate Change (IPCC); and the World Meteorological Organisation (WMO) in addition to the local water authorities. While it was anticipated that the term peak period would be difficult to define, it seems that many organisations struggle to define it at all with very few definitions found. The WSAA defines the peak day as simply the "day on which water consumption was the highest' [5]. This definition, however, does not incorporate any characteristics of the weather patterns on consecutive days. In the Gippsland region, Gippsland Water had a general understanding that the peak demand on their system is experienced when the temperature reached approximately 35 degrees Celsius for four consecutive days. Other organisations have not defined such periods even though this would affect their planning and operations in multiple ways. It was, therefore, concluded that there was no commonly accepted definition of a peak period. It is also reasonable to state that some organisations do not have any definition of a peak period.

The key question, therefore, is - whether a commonly accepted definition of a peak period is required. The authors see some benefits of having a widely recognized definition. This could assist the relevant organisations to work together and share information amongst themselves during peak periods, and that could pave the way for better management of disasters and even sharing of resources and functioning hand in hand.

\section{Peak periods and peak water demand}

Specifically, in context of water management, projecting water demand during the peak period is an important element in the design of water supply systems. An essential characteristic of any water supply system is its capacity to supply the required flow at desired pressures, even when the system is experiencing peak demand. Peak demand data is used by water authorities to adequately size water storages while the peak hourly demand is used in the design of pipe sizes. ${ }^{6}$ A study was recently completed for Gippsland Water, which aimed to update the peak demand design values ${ }^{7}$ using historical demand values from SCADA for each pressure zone. This analysis identified periods of extremely high demand across a range of different conditions, as listed below: 
a. Four consecutive days over $35^{\circ} \mathrm{C}$ with little to no rainfall.

b. Three consecutive days over $37.5^{\circ} \mathrm{C}$ with little to no rainfall.

c. 21 days with no rainfall.

d. Extreme bush fire events.

While these criteria all experienced high demand, there were some significant variations across the service region of Gippsland Water for the same selected period.

These data sets were used by Gippsland Water to plan resource management and investigate economic viability of dual supply piping schemes for general residential zones.7 Information on per capita water use and its changing trend was also collected from other service providers in Victoria-Yarra Valley Water and South East Water. ${ }^{8-13}$ Findings on criteria for peak period and trends in per day demand were used to calculate the value of peak water demand. Eventually, peak water demand was reduced from 2,000 liters/lot/day to 1,300 litres/lot/day. This reduced demand value can in future feed into the overall planning process and hence allow for better informed decision making about dual piping in future residential developments and the potential use of alternative water resources.

This illustration clearly highlights the significance of having a definition for peak periods before peak demands can be calculated and the significance of this data set on major decisions such as investments in infrastructure. In the absence of a widely accepted definition, planning for peak periods shall always be inconsistent and ad-hoc.

\section{Conclusion}

The issue of identifying peak period and peak water demand is usually localised to smaller service regions rather than states or nations because the management of consequences in case of peak periods is vested with the local authorities. However, the authors' contest that state and federal agencies still need to develop generic criteria and/or guidelines on how to define peak periods. These guidelines can then be tuned further to local conditions and needs. The authors strongly propose that a review and brainstorming be undertaken on a wider scale. This will help formulate a widely accepted definition of peak periods, which will also assist informed planning of resources and enhance preparedness for disasters including climate change adaptation.

\section{Acknowledgement}

Gippsland Water for sharing data used for analysis.

\section{Conflict of interest}

Authors declare there is no conflict of interest in publishing the article.

\section{References}

1. DELWP. Water for Victoria-Water Plan. Glen Waverly, Australia, 2016.

2. WMO. 2015 is the hottest year on record. World Meteorological Organization, Switzerland; 2016.

3. WMO. WMO confirms 2016 as hottest year on record, about $1.1^{\circ} \mathrm{C}$ above pre-industrial. World Meteorological Organization, Switzerland; 2017.

4. BOM. State of the climate 2016. Bureau of Meteorology, Australia; 2017.

5. WSAA. Water Supply Code of Australia - Melbourne Retail Water Agencies Edition Version 2.0. WSAA, Australia; 2011. p. 1-23.

6. Gippsland Water. Potable water systems design criteria. Central Gippsland Region Water Corporation, Australia; 2011.

7. Davis R, Young P, Kandra H. Analysis of Peak Demand \& Investigating the Feasibility of Potable Water Substitution. Monash University, Australia; 2017.

8. SEW. Who we serve. South East Water Corporation. Australia; 2017a.

9. SEW. Recycled water - a sustainable choice. Australia; 2017b.

10. YVW. Yare Valley Prices Water. Pricing Handbook. Australia; 2016. p. $1-30$.

11. YVW. Yare Valley Water: About us. Yarra Valley Water Corporation, Australia; 2017a.

12. YVW. Mandated recycled water areas. Yarra Valley Water Corporation, Australia; 2017b.

13. Flood Victoria. USA; 2017. 